\title{
Frequency distribution of genes encoding aminoglycoside modifying enzymes in uropathogenic $E$. coli isolated from Iranian hospital
}

Neda Soleimani $i^{*}$, Mahdi Aganj ${ }^{2}$, Liaqat Ali $^{3,4^{*}}$, Leili Shokoohizadeh ${ }^{5}$ and Türkân Sakinc ${ }^{3}$

\begin{abstract}
Background: Escherichia coli is considered as the most common cause of urinary tract infection (UTI) and acquired multiple resistances to a wide range of antibiotics such as aminoglycosides. Enzymatic alteration of aminoglycosides (AMEs) by aminoglycoside- modifying enzymes is the main mechanism of resistance to these antibiotics in E. coli. The aim of this study was detection and investigation of frequency of genes encoding aminoglycoside modifying enzymes (aac(3)-Ila and ant(2"')-la) in UPEC isolated from hospitalized patients in teaching hospital of Tehran, Iran.

Findings: A total of 276 UPEC were obtained from Urine samples in a hospital from Tehran. Antibiotic susceptibility to aminoglycosides was determined by disk diffusion method according CLSI guidelines in UPEC isolates. MICs of target antibiotics were determined by agar dilution method. All isolates were screened for the presence of the AMEs genes using the PCR. The results of disk diffusion showed 21\%, 24.6\%, 23.18\%, 3.62\% and 6.15\% of isolates were resistant to Gentamicin, Tobramycin, Kanamicin, Amikacin and Netilmicin respectively. The agar dilution's results (MICs) were high, 66.19\% for Gentamicin. The aac (3)-lla and ant(2")-la genes were detected in (78.87\%) and $47.88 \%$ of isolates respectively.
\end{abstract}

Conclusions: This study shows the high frequency of genes encoding (AMEs) aac(3)-lla and ant(2")-la genes and their relationship between different aminoglycoside resistance phenotypes.

Keywords: UPEC, Aminoglycoside modifying enzymes and UTI

\section{Background}

The aminoglycosides are potent bactericidal agents that inhibit bacterial protein synthesis by binding to the $30 \mathrm{~S}$ ribosomal subunit. They are often used in combination with either a b-lactam or a glycopeptide, especially in the treatment of Escherichia coli UTI, as these drugs act synergically $[1,2]$. The application may be limited by the appearance of resistant strains in treatment. Various mechanisms are playing a role in the development of aminoglycoside resistance but the presence of aminoglycoside modifying enzymes is the most clinical and

\footnotetext{
* Correspondence: n.soleimani@modares.ac.ir; liaqatbiotech@yahoo.com 'Department of Bacteriology, Faculty of Medical Sciences, Tarbiat Modares University, Po Box:14115-158, Tehran, Iran

${ }^{3}$ Division of Infectious Diseases, Department of Internal Medicine II, University Hospital Freiburg, Freiburg 79106, Germany

Full list of author information is available at the end of the article
}

epidemiological importance [3,4]. These enzymes are divided into three classes: aminoglycoside acetyltrans- ferases (AACs), aminoglycoside phosphotransferases (APHs) and aminoglycoside nucleotidyltransferases (ANTs) [5].

Urinary tract infection is one of the most common human infections, especially in young women and frequently influenced by sex and age and $20-30 \%$ of young women experienced this infection [6,7]. Due to the importance of the resistance to aminoglycosides and the role of ant(2)-Ia, aac(3)II-a genes in mechanism, the main purpose of this study is the detection of resistance genes ant(2")-Ia, aac(3) II-a in clinical isolates of aminoglycoside resistant E. coli isolated from urine of hospitalized patients in teaching hospital of Tehran, Iran, to know the prevalence and 
frequency of distribution of genes encoding aminoglycoside in Iranian population.

\section{Materials and methods Sample collection}

A total of 276 clinical isolates of $E$. coli from urine specimens were randomly collected from Tehran Heart center. All isolates were then identified as E.coli using conventional microbiological tests. Informed written consent was obtained from the patients and the study was approved by the institutional ethics committee of Department of Bacteriology, Faculty of Medical Sciences, Tarbiat Modares University, Tehran. Pure stock cultures of all isolates were stored frozen at $-80^{\circ} \mathrm{C}$ in tryptic soy broth, containing $15 \%$ glycerol.

\section{Antibiotic susceptibility testing}

Antimicrobial susceptibility test for different E.coli isolates was performed against Gentamicin $(10 \mu \mathrm{g})$, Tobramycin $(10 \mu \mathrm{g})$, Kanamycin $(30 \mu \mathrm{g})$, Amikacin $(30 \mu \mathrm{g})$ and Nethelmicin $30 \mu \mathrm{g}$, (Mast, UK) by disc diffusion method. Sizes were interpreted using standard recommendations of CLSI [8]. As the Gentamicin is the most applicable antibiotics to treat the infections due to gram positive and gram negative bacteria in Iranian patients, thus, Gentamicin MIC values were detected and the results were interpreted according to the CLSI guidelines.

\section{DNA extraction and Polymerase Chain Reaction}

Total DNAs were extracted from bacteria isolates using the extraction kit (Bioneer, korea). The DNA was then extracted following the manufacturer's instructions and electrophoresed on $0.8 \%$ agarose gel stained with ethidium bromide and visualized by UV-transillumination and gel documentation (Biometra Germani). Two sets of specific oligonucleotide primers for (aac(3)-IIa and ant $\left(2^{\prime \prime}\right)$-Ia) genes were used as listed in Table 1 (designated by primer 3 software). The PCR mixture was prepared in a final volume of $25 \mu \mathrm{l}$. The amplification mixture consisted of template DNA $(2 \mu \mathrm{l}), 0.1 \mu \mathrm{M}$ of the respective primers, $2.5 \mu \mathrm{l}$ of a 10 -fold concentrate PCR

Table 1 Primer sequences for aminoglycoside resistance genes detection

\begin{tabular}{lcc}
\hline Primers & Sequence $\mathbf{( 5}^{\prime}$-3') & Length \\
\hline Fragment (700 bp) & & \\
ant(2")-la fw & TCCAGAACCTTGACCGAAC & 19 \\
ant(2")-la rev & GCAAGACCTCAACCTTTCC & 20 \\
Fragment (740 bp) & & \\
aac(3)--lla fw & CGGAAGGCAATAACGGAG & 18 \\
aac(3)--lla rev & TCGAACAGGTAGCACTGAG & 19 \\
\hline
\end{tabular}

buffer, $200 \mu \mathrm{M}$ of deoxynucleotide triphosphates, $2.5 \mu \mathrm{M}$ $\mathrm{MgCl} 2$, and 1.5 U of Taq DNA polymerase (Cinna Gene). A thermocycler (Mastercycler gradient; Eppendorf, Hamburg, Germany) was programmed with the following parameters: after an initial denaturation for $5 \mathrm{~min}$ at $95^{\circ} \mathrm{C}$, 30 cycles of amplification were performed with denaturation at $95.8^{\circ} \mathrm{C}$ for $1 \mathrm{~min}$, annealing at $62^{\circ} \mathrm{C}$ for $1 \mathrm{~min}$, and DNA extension at $72^{\circ} \mathrm{C}$ for $1 \mathrm{~min}$, followed by a final extension at $72^{\circ} \mathrm{C}$ for $10 \mathrm{~min}$. Then, 5 to $10 \mu \mathrm{l}$ of the PCR products was analyzed by electrophoresis on $0.8-1 \%(\mathrm{w} / \mathrm{v})$ TAE agarose gel (Fermentas UAB, Vilnius, Lithuania) containing $0.5 \mu \mathrm{l} / \mu \mathrm{l}$ of ethidium bromide. Stained amplicons were then viewed on a UV transilluminator at $260 \mathrm{~nm}$, (BioDoc- Analyse; Biometra, Goettingen, Germany). klebsiella pneumoniae 23823 [possessing (aac(3)-IIa+)] and E. coli 85085 [possessing (ant(2")-Ia+)] by Statens Serum Institute of Denmark served as positive controls and E. coli ATCC 25922 as negative control (Table 1).

\section{Findings}

\section{Antimicrobial susceptibility}

Antibiotic resistance analysis showed among 276 E.coli isolated from clinical specimens, simultaneous resistance to gentamicin, nethelmicin and kanamicin in 39\% of isolates was the most common antibiotic resistance pattern among isolates under study (Table 2). The range of MIC for $5 \%$ Gentamicin was from $1 \mu \mathrm{g} / \mathrm{ml}$ to $512 \mu \mathrm{g} / \mathrm{ml}$. MIC $\geq 64$ were detected in more than $35 \%$ of isolates. Some isolates showed MIC of $>512 \mathrm{ug} / \mathrm{ml}$. All antibiotic sensitivity/resistance of $E$. coli strains isolated from the urine clinical specimens are shown in Figure 1.

\section{Amplification and screening of genes encoding AME by PCR}

All isolates were screened for the presence of genes encoding the two AMEs, enzymes (AAC(3)-IIa and ANT(2')-Ia). Amplified DNA fragments of two different sizes (700 and $740 \mathrm{bp}$ ) were subjected to agarose gel electrophoresis and snapped by gel picture (Figures 2

Table 2 Antibiotic resistance patterns (\%) of E. coli isolates

\begin{tabular}{llc}
\hline $\begin{array}{l}\text { Number of antibiotics resistant } \\
\text { and showing pattern }\end{array}$ & Number of strains \\
\hline Single antibiotic & & $3(4.22 \%)$ \\
Two antibiotics & GM,TN $(n=4)$ or & $17(23.94 \%)$ \\
& GM,K $(n=13)$ & $28(39.43 \%)$ \\
Three antibiotics & GM,TN, K & $19(26.76 \%)$ \\
Four antibiotic & GM,N,TN,K $(n=13)$ or & \\
& GM,AK,TN,K $(n=6)$ & $4(5.63 \%)$ \\
\hline
\end{tabular}

GM, gentamicin; AK, amikacin; N, netilmicin; TN, tobramycin; K, kanamycin. 


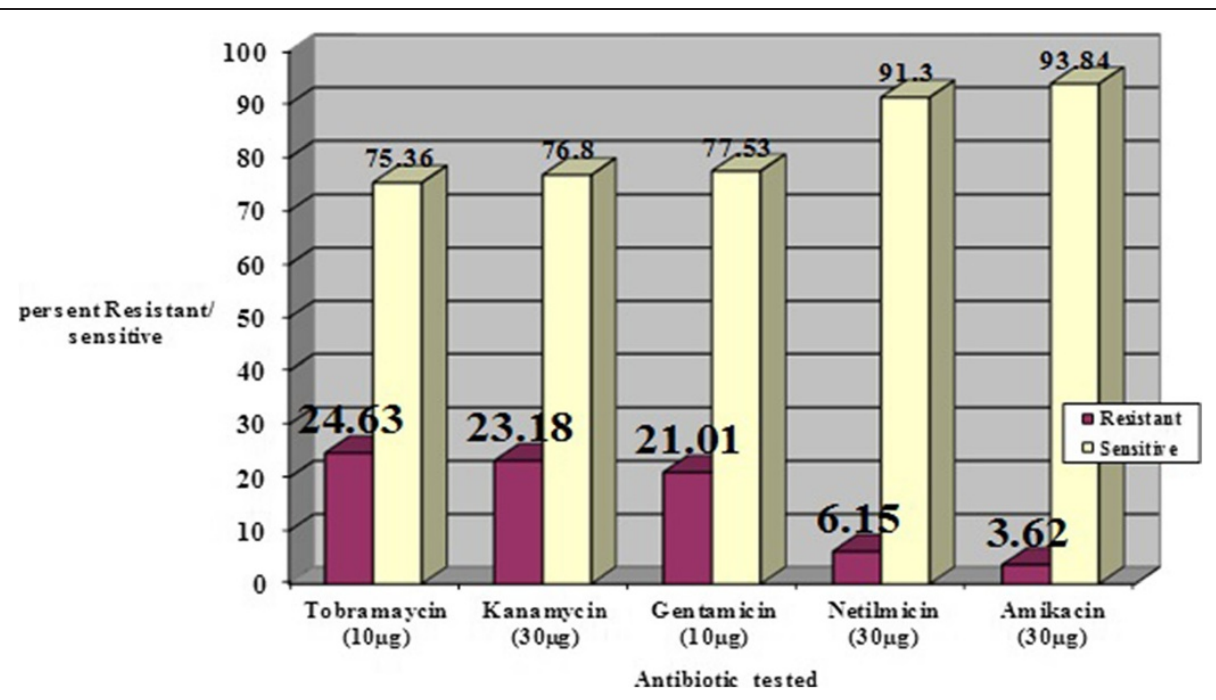

Figure 1 Antibiotic sensitivity/resistance of $E$. coli strains isolated from the urine clinical specimens $(n=276)$.

and 3). Based on PCR results, The prevalence of aac(3)IIa gene and ant(2")-Ia gene were $47.88 \%$ and $78.87 \%$ respectively $32.39 \%$ of isolates only harbored the aac(3)-IIa and $7.04 \%$ ant(2")-Ia. In addition our results, demonstrated the relationship between AME genes and different aminoglycoside resistance phenotypes (Table 3).

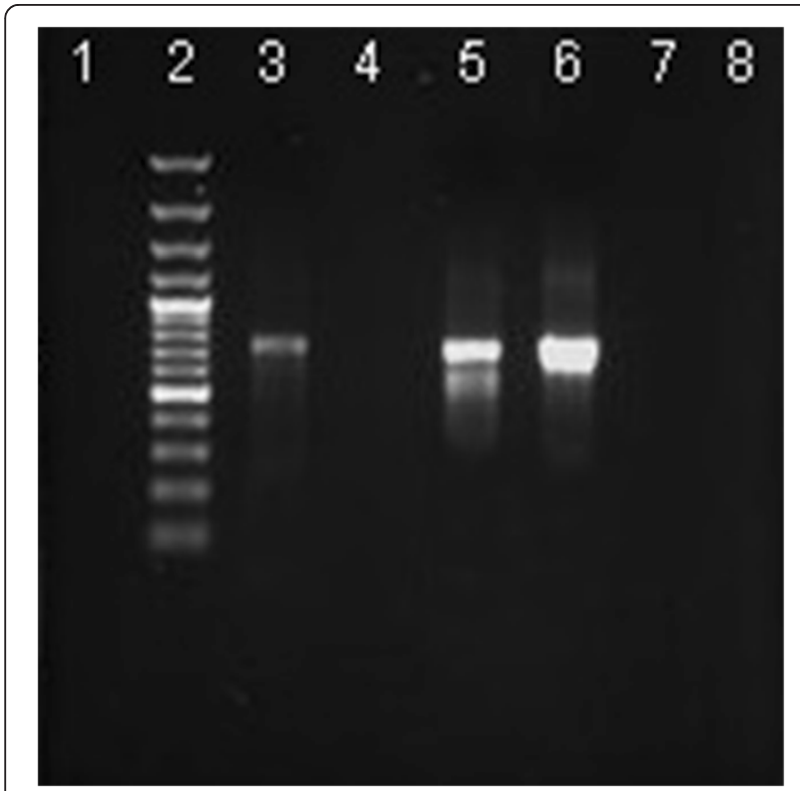

Figure 2 Agarose gel electrophoresis of amplified DNA fragments by PCR from reference strains and clinical isolates of E. coli. Lanes: 2, 100 bp Plus DNA ladder (GeneRuler_; Fermentas); 1, E. coli ATCC 25922 as negative control; 3, 23823 [aac(3)-Ila+] both were used as positive controls; $4-8$, clinical isolates of $E$. coli.

\section{Discussion}

Besides the side effects and increasing resistance, aminoglycosides play an important role in curing bacterial infections. Modification of aminoglycosides by aminoglycosides modifying enzymes is the common resistance mechanism against aminiglycosides in E.coli as these enzymes are not capable of binding to ribosomes of the cell $[9,10]$. Resistance against Gentamicin, Kanamycin, Cizomycin and Tobramycin is mediated by ANT(2")-Ia enzyme which is coded by ant(2")-Ia gene in E.coli and also simultaneous resistance to Gentamycin and Tobramycin, mediated by AAC(3)-IIa enzyme which is coded by aac(3)-IIa gene [11].

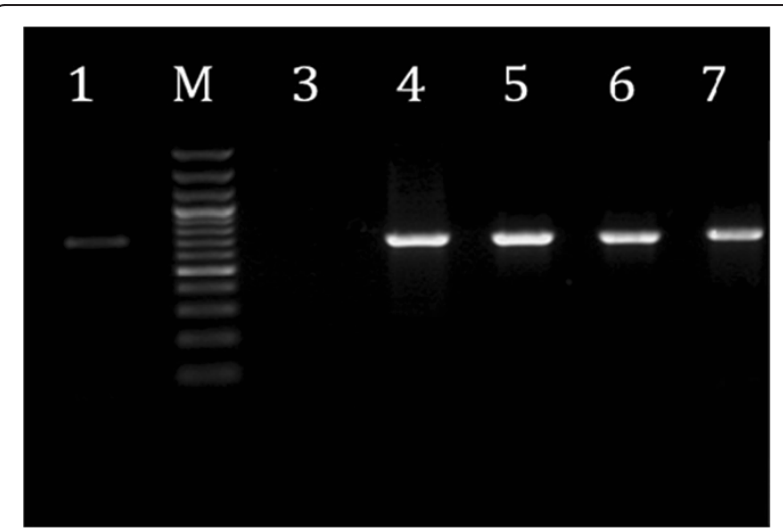

Figure 3 Agarose gel electrophoresis of amplified DNA fragments by PCR from reference strains and clinical isolates of E. coli. Lanes: M, 100 bp Plus DNA ladder (GeneRuler; Fermentas); 3, E. coli ATCC 25922 as negative control; 1, E. coli 85085 [(ant(2")-la+)] both were used as positive controls; 4-7, clinical isolates of $E$. coli. 


Table 3 Relationship between AME genes and different
resistance Aminoglycosid patterns
\begin{tabular}{ccc}
\hline $\operatorname{aac}(3)-l l a$ & ant(2")la & Resistant phenotype \\
\hline+ & + & $\mathrm{GM}, \mathrm{AK}, \mathrm{N}, \mathrm{TN}, \mathrm{K}$ \\
+ & + & $\mathrm{GM}, \mathrm{AK}, \mathrm{N}, \mathrm{TN}, \mathrm{K}$ \\
+ & + & $\mathrm{GM}, \mathrm{N}, \mathrm{TN}, \mathrm{K}$ \\
+ & - & $\mathrm{GM}, \mathrm{N}, \mathrm{TN}, \mathrm{K}$ \\
+ & + & $\mathrm{GM}, \mathrm{TN}$ \\
- & + & $\mathrm{TN}, \mathrm{K}$ \\
+ & + & $\mathrm{GM}, \mathrm{TN}, \mathrm{K}$ \\
+ & - & $\mathrm{TN}$ \\
- & + & $\mathrm{K}$ \\
- & - & $\mathrm{N}$ \\
+ & - & $\mathrm{GM}$ \\
- & - & $\mathrm{AK}$ \\
\hline
\end{tabular}

${ }^{*} \mathrm{GM}$, gentamicin; AK, amikacin; N, netilmicin; TN, tobramycin; K, kanamycin; + , present; -.

In this study the prevalence of ant(2")-Ia,aac(3)-IIa resistance genes in 71 aminoglycosides resistant E.coli isolates among 276 UTI isolates was determined by PCR. It is implied that $24.63 \%$ of isolates were resistant to tobramycin and the resistance rate against other 130 antibiotics were as following; Kanamycin 23.18\%, Gentamicin 21.01\%, Netilmicin 6.15\% and Amikasin 3.62\%. In 1999 Van hoof R and his colleagues reported that among 897 blood 132 isolates of Entrobacteriacea, 5.9\% of isolates were resistance against Gentamycin, whereas $7.7 \%$ of isolates were resistant against Tobramycin,7.5\% against netilmicin and 8.2\% against Amikacin [11,12]. In 2006 Kong and 2010 Lang Hoo and colleagues reported: 44 clinicalisolates of E.coli, the resistance rate against aminiglycosides were: Amikasin 18.18\%, Gentamicin 56.82\% and Tobramycin 63.36\% and among 249 clinical isolates of E.coli $83.83 \%$ were resistant to Gentamicin respectively $[13,14]$.

The respective studies suggested an increasing resistance against aminoglycosides but the contradiction in results is due to different geographical areas and various numbers of different isolates. PCR results showed that $78.87 \%$ of isolates contained aac(3)-IIa resistance gene. In 2004 , Minard showed that $17 \%$ of animal and $33 \%$ of human isolates contained the aac(3)-IIa resistance gene, aph(3)-Ia was detected in $6.97 \%$ and $4 \%$ of human isolates of Kanamycin resistant. Also, E.coli in $8 \%$ of animal isolates and $7.04 \%$ of human isolates of neomycin resistant while ant(2")-Ia gene was not detected in this study [7]. Jaconson et al. [15] studied 120 isolates of E. coli for occurrence of amino glycoside modifying enzymes namely ant(2")-Ia, aac(3)-IIa and aac(3)-IV and also subjected the isolates to MIC for Gentamicin by dilution method. The E.coli isolates having aac(3)-IIa gene had high MIC's, 32-512 mgs/ltr suggesting that, there is a correlation between MIC and specific ame production, but still not cleared [14]. Jacobson et al. also studied 76 isolates of Gentamicin resistant E. coli which are 63.15\% and contained aac(3)-IIa gene, although, ant(2")-Ia gene was not screened in this study [15]. In an epidemiological study in 2010 it was concluded that aac(3)-IIa (aaC2) gene was present in $84.1 \%$ of human isolates and $75.5 \%$ of animal isolates, while it was the common gene among the studied isolates [16].

Therefore, our results shows high frequency prevalence of aac(3)-IIa and ant(2")-Ia genes, which were $47.88 \%$ and $78.87 \%$ respectively and also, demonstrated the relationship between AME genes and different aminoglycoside resistance phenotypes. According to the reviewed studies the prevalence of the respective genes has been increasing over time in various geographical patterns, which needs regular attention and determination.

\section{Conclusions}

In conclusion, our data show high frequency distribution of aac(3)-IIa and ant(2")-Ia genes and their relationship between AME genes and different aminoglycoside resistance phenotypes. Further experiments will be needed to clarify the exact mechanisms and functions of these genes to controlled high prevalence of urinary tract infections caused by EPEC strains, increasing resistance against antibiotics in order to select the best medicine to avoid this confrontation.

\section{Competing interests}

The authors declare that they have no competing interests.

\section{Authors' contributions}

NS and LA conceived the study. NS conducted the experiments and analyzed the results. LA drafted the manuscript and made substantial contributions to the design of the study. TS, MA and LS critically reviewed the manuscript and participated in data analysis. All the authors studied and approved the final manuscript.

\section{Acknowledgement}

This study was generously funded by tarbiat Modares University. The author LA sincerely thanks to DAAD for awarding a PhD Fellowship.

\section{Author details}

${ }^{1}$ Department of Bacteriology, Faculty of Medical Sciences, Tarbiat Modares University, Po Box:14115-158, Tehran, Iran. ²Department of Microbiology, Mashhad University of medical sciences, Faculty of Medical Sciences, student research committee, Mashhad, Iran. ${ }^{3}$ Division of Infectious Diseases, Department of Internal Medicine II, University Hospital Freiburg, Freiburg 79106, Germany. ${ }^{4}$ Faculty of Biology, Albert Ludwigs University of Freiburg, Schänzlestraße 1, Freiburg 79104, Germany. ${ }^{5}$ Department of laboratory medical Sciences, Faculty of Para Medical Sciences, Ahvaz Jondishapour, University of medical sciences, Ahvaz, Iran.

Received: 16 February 2014 Accepted: 18 November 2014 Published: 25 November 2014 


\section{References}

1. Dornbusch K, Miller GH, Hare RS, Shaw KJ: Resistance to aminoglycoside antibiotics in gram- negative bacilli and Staphylococci isolated from blood. The ESGAR Study Group (European Study Group on Antibiotic Resistance). J Antimicrob Chemother 1990, 26:131-144.

2. Schmitz FJ, Jones ME: Antibiotics for treat- ment of infections caused by MRSA and elimination of MRSA carriage. What are the choices? Int J Antimicrob Agents 1997, 9:1-19.

3. Udo EE, Dashti AA: Detection of genes en- coding aminoglycosidemodifying enzymes in Staphylococci by polymerase chain reaction and dot blot hybridization. Int J Antimicrob Agents 2000, 13:273-279.

4. Shaw KJ, Hare RS, Sabatelli FJ, Rizzo M, Cramer CA, Miller GH, Verbist L, Van Landuyt H, Glupczynski Y, Catalano M, Woloj M: Correlation between aminoglycoside resistance profiles and DNA hybridization of clinical isolates. Antimicrob Agents Chemother 1991, 35:2253-61.

5. Yadegar A, Sattari M, Nour Amir M, Gholam Reza G: Prevalence of the Genes Encoding Aminoglycoside-Modifying Enzymes and Methicillin Resistance Among Clinical Isolates of Staphylococcus aureus in Tehran, Iran. Microb Drug Resist 2009, 15:109-113.

6. Von Baum H, Marre R: Antimicrobial resistance of Escherichia coli and therapeutic implications. Intern J Med Microbiol 2005, 295:503-511.

7. Santo E, Mendonca Salvador M, Moacir MJ: Multidrug-Resistant Urinary Tract Isolates of Escherichia coli from Ribeirão Preto, São Paulo, Brazil. Brazilian J Infect Dis 2007, 11:575-578.

8. Clinical and Laboratory Standards Institute/NCCLS: Performance standards for antimicrobial susceptibility testing; seventeenth informational supplement. Wayne, PA: CLSI/NCCLS document M100-S17. CLSI; 2007.

9. Bellaaj A, Bollet $\mathrm{C}$, Ben-Mahrez K: Characterization of the 3-N-aminoglycoside acetyltransferase gene aac(3)-Ila of a clinical isolate of Escherichia coli. Annal Microbiol 2003, 53:211-217.

10. Choi SM, Kim SH, Kim HJ, Lee DG, Choi JH, Yoo JH, Kang JH, Shin WS, Kang MW: Multiplex PCR for the detection of genes encoding aminoglycoside modifying enzymes and methicillin resistance among Staphylococcus species. J Korean Med Sci 2003, 8:631-636.

11. Chandrakanth RK, Raju S, Patil SA: Aminoglycoside-resistance mechanisms in multidrug-resistant Staphylococcus aureus clinical isolates. Curr Microbiol 2008, 56:558-562

12. Vanhoof RJ, Nyssen H, Van Bossuyt E, Hannecart-Pokorni E, and the Aminoglycoside Resistance Study Group: Aminoglycoside resistance in Gram-negative blood isolates from various hospitals in Belgium and the Grand Duchy of Luxembourg. J Antimicrob Chemother 1999, 44:483-488.

13. Kong HS, Li XF, Wang JF, Wu MJ, Chen X, Yang Q: Evaluation of aminoglycoside resistance phenotypes and genotyping of acetyltransferase in Escherichia coli. Zheijang J 2006, 35:83-6.

14. Leung Ho PC, Wong RW, Lo S, Chow KS, Wong S, Lun Que T: Genetic identity of aminoglycoside resistance genes in Escherichia coli isolates from human and animal sources. J Med Microbiol 2010, 34:145-155.

15. Jakobsen L, Sandvang DF, Jensen VM, Seyfarth A, Frimodt-Moller NM, Hammerum A: Gentamicin susceptibility in Escherichia coli related to the genetic background: problems with breakpoints. Clin Microbiol Infect 2007, 13:816-842.

16. Jakobsen L, Dorthe S, Lars HH, Line B, Henrik W, Claus J, Dennis SH, Bodil MP, Dominique LM, Niels F, Søren JS, Anette MH: Characterization, dissemination and persistence of gentamicin resistant Escherichia coli from a Danish university hospital to the waste water environment. Environ Intern Microbiol 2008, 34:108-115.

\section{Submit your next manuscript to BioMed Central and take full advantage of:}

- Convenient online submission

- Thorough peer review

- No space constraints or color figure charges

- Immediate publication on acceptance

- Inclusion in PubMed, CAS, Scopus and Google Scholar

- Research which is freely available for redistribution

Submit your manuscript at www.biomedcentral.com/submit 